\title{
The influence of negative illness cognitions and neuroticism on subjective symptoms and mood in rheumatoid arthritis
}

\section{L-O Persson, D Sahlberg}

See end of article for authors' affiliations

Correspondence to: Correspondence to:
Dr Lars-Olof Persson, Health Care Research Unit, Institute of Internal Medicine, Sahlgrenska University Hospital, S-413 45 Göteborg, Sweden; lars.persson@fhs.gu.se

Accepted 17 April 2002
Background: It was hypothesised that negative RA related illness cognitions are strongly related to the neuroticism trait and act as a common factor behind other self reported subjective symptoms (pain and ADL status), mood, and positive RA related illness cognitions; but are unrelated to objective indices of impairment (disease duration, $C$ reactive protein (CRP), and joint stiffness).

Objective: To examine the relative influence of negative illness cognitions and neuroticism versus degree of impairment on subjective symptoms, positive illness cognitions, and mood in rheumatoid arthritis (RA).

Methods: Structural equation modelling analyses (LISREL) were performed on two independent samples of patients with RA consisting of 212 outpatients and 105 inpatients, respectively.

Results: The hypotheses were largely confirmed. Firstly, negative RA cognitions were found to be dependent on neuroticism. Secondly, negative RA cognitions had a strong and dominating influence on all other self reported data. Subjective symptoms were equally well explained by negative RA cognitions as by degree of impairment. No relations were found between negative RA cognitions (or neuroticism) and degree of impairment.

Conclusions: The findings suggest that neuroticism, recognised as a relatively stable personality trait, strongly influences self rated symptoms and wellbeing in RA. This has important clinical implications concerning the use of standardised self rating questionnaires commonly used to assess illness status in RA and the long term effectiveness of psychological interventions and patient training courses in RA rehabilitation.
D uring the 1980s and 1990s several attempts were made to clarify reasons for emotional wellbeing or distress among patients with rheumatoid arthritis (RA). One major finding was that indicators of severity of disease, such as inflammatory activity and physical disability, ${ }^{1-6}$ had surprisingly low correlations with emotional state. This in turn led to an interest in psychological factors that were hypothesised to moderate or inflate the presumed effects of the physical expressions of RA on emotional state. Initially guided by cognitive and behavioural theories of depression, stress, and coping, this research focused particularly on the constructs learned helplessness, ${ }^{7-10}$ self efficacy beliefs, ${ }^{11-15}$ cognitive distortions, ${ }^{16-20}$ and coping. ${ }^{21-29}$ On closer examination, however, it was found that these constructs could only partially explain individual variations in emotional state. ${ }^{56}$

More recent research has shown that relatively stable personality traits, particularly what has been labelled negative affect or neuroticism, are relatively strongly associated with a broad range of subjective experiences and cognitions and may act as a common factor behind several types of perceptions or experiences. ${ }^{30-32}$ Thus, those high in neuroticism seem to be more perceptive of physical sensations, ${ }^{33}$ to interpret physical symptoms as more threatening, ${ }^{34}$ to experience more emotional distress over time regardless of the objective situation, ${ }^{35}$ to react more strongly to negative events, and to choose and use less effective coping strategies. ${ }^{36}{ }^{37}$ In a prospective study of patients with RA, Affleck et al also showed that neuroticism, compared with other psychological variables, is the strongest determinant of low mood..$^{38}$ In a review of the research literature, Clark et al broadly characterised neuroticism as follows: "We conceptualize the core of this dimension to be a temperamental sensitivity to negative stimuli, thereby causing high trait scorers to experience a broad range of negative moods, including not only fear/ anxiety and sadness/depression, but also such emotions as guilt, hostility and self-dissatisfaction. A wide range of non-mood variables are related to this affective core, including negative cognitions, somatic complaints, negativistic appraisal of self and others, diverse personality characteristics such as pessimism and low self-esteem." ${ }^{\prime 39}$

The suggestions that a stable temperamental trait may influence most types of self reported data have important implications for clinical practice in rheumatic conditions, as illness status is now commonly assessed by standardised self rating questionnaires, such as pain by a visual analogue scale (VAS) and functional status by the Health Assessment Questionnaire (HAQ) scale. ${ }^{4041}$ The extent that neuroticism, assumed to be unrelated to objective indicators of illness status (impairment), confounds such measures is an important issue to resolve. Furthermore, if patient differences in subjective illness status and emotional wellbeing largely depend on stable temperamental dispositions then efforts to change patients' illness cognitions or coping strategies would be expected to have little impact in the long run. In a review of psychological intervention programmes, DeVellis and Blalock also concluded that the positive effects initially achieved by psychological interventions seemed to disappear over time. ${ }^{42}$

In a newly developed questionnaire, ${ }^{6}$ RA self conceptions (RASC), three negative and three positive dimensions of RA

Abbreviations: CRP, $\mathrm{C}$ reactive protein; $\mathrm{df}$, degrees of freedom; $\mathrm{GFI}$, goodness of fit index; $\mathrm{HAQ}$, Health Assessment Questionnaire; MACL, mood adjective check list: RA, rheumatoid arthritis; RASC, RA self conceptions; RMSEA, root mean square error of approximation; SEM, structural equation modelling; VAS, visual analogue scale 
related cognitions were identified. It was suggested that these cognitions should be conceptualised as knowledge structures, ${ }^{43}{ }^{44}$ specific for the situation of living with RA, which have developed as a result of an interaction between personality styles, stress imposed by the disease, psychosocial resources, and other situational factors encountered during the course of the illness. They are defined as cognitive/affective programmes used for interpreting and evaluating specific encounters, directing attention, and guiding behaviour. ${ }^{43} 44$

The content of the negative RA cognitions (deprivation of lost life values, reserved and protest), and their rather strong intercorrelations ${ }^{6}$ led us also to hypothesise that they are closely associated with the neuroticism trait as described above by Clark et al..$^{39}$ On the other hand, the three positive dimensions (fighting spirit, revaluation of life values, and acceptance), were interpreted as more related to coping efforts-for example, cognitions aimed to overcome the negative experiences of the illness. Many of the items in these dimensions tap similar types of cognitions that are described in the literature as coping. ${ }^{11}{ }^{13} 22-28$ 45-47

The overall aim of the present study was to examine whether the negative RA cognitions, measured by the three negative dimensions of the RASC questionnaire and assumed to be related to the neuroticism trait, may act as a strong common factor behind other self reported data relevant for perceived health status among patients with RA. The specific aims were $(a)$ to examine the degree that these negative RA cognitions influence the positive RA cognitions (measured by the RASC questionnaire), subjective symptoms (pain and ADL status), and emotional wellbeing (mood); $(b)$ to examine if the negative RA cognitions are related to objective measures of illness status (impairment) and; (c) to examine the degree that neuroticism is associated with the negative RA cognitions.

\section{METHODS \\ Patients}

Analyses were performed on data obtained from two independent samples (henceforth sample 1 and sample 2) of patients with RA, described more fully in an earlier study. ${ }^{6}$ Briefly, all patients were diagnosed as having definite or classic RA according to the American Rheumatism Association criteria of $1987 .^{48}$ Sample 1 consisted of 212 consecutive patients with RA (78\% women), who were examined at their routine visit at the outpatient department of rheumatology at the University Hospital of Lund. The patients' mean age was 52.6 (SD 10.8) years; range 25-67 years) and mean disease duration was 14.5 (SD 10.9) years; range 1-47 years). Sample 2 consisted of 120 consecutive patients with RA ( $89 \%$ women) referred to Spenshult's Hospital for Rheumatic Diseases for a one month rehabilitation stay. Their mean age was 60.2 (SD 11.5) years; range 24-80 years) and mean disease duration was 15.4 (SD 10.7) years; range $1-50$ years).

\section{Measures}

\section{Illness status}

These measures were divided into two subtypes: self rated measures assessing subjective experiences of disability and handicap; and objective measures assessing degree of impairment at the time of measurement. According to the International Classification of Impairment, Disabilities and Handicaps (World Health Organisation 1980), impairment is defined as organ affections (for example, arm or leg); disability refers a person's inability to perform normal duties; and handicap is defined as the inability to do things that are important for the specific person.

In both samples, perceived pain and activity limitations were used as subjective measures of the impact of the illness. Pain was measured by a $100 \mathrm{~mm}$ VAS and activity limitations by a Swedish version ${ }^{40}{ }^{41}$ of the Stanford HAQ.
Degree of impairment was assessed using a summated index consisting of disease duration (number of years since diagnosis); serum $\mathrm{C}$ reactive protein (CRP) as a biochemical estimate of inflammatory activity; and a count of the number of swollen joints assessed by an independent rheumatologist. In sample 2 the last indicator was replaced by Ritchie's articular index, which is a standardised rheumatological assessment of the tenderness of 26 predefined joints. ${ }^{49}$ It was assumed that it is more likely that a patient with a combination of long duration of disease, high levels of CRP, and several affected joints has a more advanced disease from a medical point of view than a patient with lower scores on any one of the indicators. Each of these indicators were standardised to a uniform scale and added to construct a single index of impairment.

\section{Psychological questionnaires}

Subjective wellbeing was measured by the Swedish mood adjective check list (MACL), which has been widely used in Sweden as a measure of emotional wellbeing and is fully described elsewhere..$^{50-53}$ The shortened version, which was used in the present study, consists of 38 mood adjectives measuring three bipolar mood dimensions: Pleasantnessunpleasantness (for example, happy, sad); activation-passivity (for example, active, tired) and calmness-tension (for example, calm, nervous). These three scales were used as variables of subjective wellbeing.

The primary focus in this study was on the RASC. This instrument was developed as a 44 item descriptor of the patients' views on how the disease had influenced them and their lives. ${ }^{6}$ Briefly, the questionnaire was constructed from statements derived from interviews with patients with RA on their experiences of living with the disease. Multivariate analyses resulted in a hierarchical model consisting of six primary factors and one negative and one positive secondary factor, which showed a good fit to observed data in two independent samples. The three primary factors with negative content were labelled "deprivation of lost life values", "reserved", and "protest". The three with positive content were called "fighting spirit", "revaluation of life values", and "acceptance".

The third psychological questionnaire was a Swedish version of the Eysenck Personality Inventory. ${ }^{545}$ The 24 item scale measuring neuroticism was used to assess degree of trait neuroticism. Scores on this test were only available from sample 2.

\section{Statistical analyses}

All tests were performed by means of structural equation modelling (SEM) analyses..$^{56-60}$ LISREL VIII software was used..$^{57}$ Covariances between the variables were used as input. Estimates were calculated using the maximum likelihood method, which is considered to be robust against deviations from normality. ${ }^{57}{ }^{59}$ Listwise deletion of missing values gave effective sample sizes of 212 for sample 1 and 105 for sample 2. Among the several indices of goodness of fit provided by LISREL VIII, ${ }^{57}$ those chosen for model selection were the $\chi^{2}$ value, the root mean square error of approximation (RMSEA), and the goodness of fit index (GFI). According to conventions in SEM analyses ${ }^{56}{ }^{59}$ a model was viewed as acceptable if it had a $\chi^{2} /$ degrees of freedom ( $\mathrm{df}$ ) ratio less than 3, an RMSEA value below 0.07, and a GFI above 0.9. The SEM models were initially tested on sample 1 because of the larger number of patients in this group and were then cross validated on sample 2 .

\section{RESULTS}

Mean values, standard deviations (SDs), and correlations between variables

Table 1 shows mean values, SDs, and product-moment correlations for the two samples. Despite demographic and clinical 
Table 1 Correlations between observed variables, mean values, and SDs (the coefficients from sample 1 are shown above those for sample 2)

\begin{tabular}{|c|c|c|c|c|c|c|c|c|c|c|c|c|c|c|}
\hline & 1 & 2 & 3 & 4 & 5 & 6 & 7 & 8 & 9 & 10 & 11 & 12 & 13 & 14 \\
\hline \multicolumn{15}{|l|}{ (1) Duration } \\
\hline (2) CRP & $\begin{array}{l}0.17^{* *} \\
-0.06\end{array}$ & & & & & & & & & & & & & \\
\hline $\begin{array}{l}\text { (3) Joints } \\
\text { Ritchie }\end{array}$ & $\begin{array}{r}-0.11 \\
0.07\end{array}$ & $\begin{array}{l}0.21^{* *} \\
0.17\end{array}$ & & & & & & & & & & & & \\
\hline (4) Pain & $\begin{array}{l}0.13 \\
0.04\end{array}$ & $\begin{array}{l}0.30^{* *} \\
0.27^{* *}\end{array}$ & $\begin{array}{l}0.12 \\
0.26^{* *}\end{array}$ & & & & & & & & & & & \\
\hline (5) $\mathrm{HAQ}$ & $\begin{array}{l}0.36^{* *} \\
0.20^{*}\end{array}$ & $\begin{array}{l}0.46^{* *} \\
0.25^{* *}\end{array}$ & $\begin{array}{l}0.05 \\
0.17\end{array}$ & $\begin{array}{l}0.39^{* *} \\
0.45^{* *}\end{array}$ & & & & & & & & & & \\
\hline (6) Depr & $\begin{array}{c}0.08 \\
-0.18^{*}\end{array}$ & $\begin{array}{l}0.15^{*} \\
0.01\end{array}$ & $\begin{array}{r}0.10 \\
-0.10\end{array}$ & $\begin{array}{l}0.26^{* *} \\
0.26^{* *}\end{array}$ & $\begin{array}{l}0.44^{* *} \\
0.16\end{array}$ & & & & & & & & & \\
\hline (7) Reserv & $\begin{array}{r}0.09 \\
-0.03\end{array}$ & $\begin{array}{c}0.04 \\
-0.23^{\text {** }}\end{array}$ & $\begin{array}{r}0.11 \\
-0.05\end{array}$ & $\begin{array}{l}0.20 \text { ** } \\
0.14\end{array}$ & $\begin{array}{l}0.27^{* *} \\
0.01\end{array}$ & $\begin{array}{l}0.64^{* *} \\
0.41^{* *}\end{array}$ & & & & & & & & \\
\hline (8) Protest & $\begin{array}{l}-0.02 \\
-0.24^{* *}\end{array}$ & $\begin{array}{l}0.10 \\
0.06\end{array}$ & $\begin{array}{c}0.06 \\
-0.19^{*}\end{array}$ & $\begin{array}{l}0.21^{* *} \\
0.11^{2}\end{array}$ & $\begin{array}{l}0.22^{* *} \\
-0.01\end{array}$ & $\begin{array}{l}0.58^{* *} \\
0.61^{* *}\end{array}$ & $\begin{array}{l}0.31^{* *} \\
0.40^{* *}\end{array}$ & & & & & & & \\
\hline (9) Fight & $\begin{array}{l}0.04 \\
0.16\end{array}$ & $\begin{array}{l}-0.14^{*} \\
-0.06\end{array}$ & $\begin{array}{l}-0.20^{* *} \\
-0.03\end{array}$ & $\begin{array}{l}-0.07 \\
-0.21^{* *}\end{array}$ & $\begin{array}{l}-0.07 \\
-0.23^{* *}\end{array}$ & $\begin{array}{l}-0.31^{* *} \\
-0.40^{* *}\end{array}$ & $\begin{array}{l}-0.30 * * \\
-0.17\end{array}$ & $\begin{array}{l}-0.10 \\
-0.20^{\star}\end{array}$ & & & & & & \\
\hline (10) Accept & $\begin{array}{l}0.23^{* *} \\
0.25^{* *}\end{array}$ & $\begin{array}{l}-0.05 \\
-0.12\end{array}$ & $\begin{array}{l}-0.07 \\
-0.03\end{array}$ & $\begin{array}{l}-0.08 \\
-0.19^{*}\end{array}$ & $\begin{array}{l}-0.10 \\
-0.03\end{array}$ & $\begin{array}{l}-0.51^{* *} \\
-0.40^{* *}\end{array}$ & $\begin{array}{l}-0.37^{* *} \\
-0.28^{* *}\end{array}$ & $\begin{array}{l}-0.33^{* *} \\
-0.37^{* *}\end{array}$ & $\begin{array}{l}0.55^{\star *} \\
0.55^{* *}\end{array}$ & & & & & \\
\hline (11) Reval & $\begin{array}{l}0.09 \\
0.14\end{array}$ & $\begin{array}{l}-0.04 \\
-0.18^{*}\end{array}$ & $\begin{array}{c}-0.17^{*} \\
0.03\end{array}$ & $\begin{array}{l}-0.10 \\
-0.09\end{array}$ & $\begin{array}{l}-0.02 \\
-0.12\end{array}$ & $\begin{array}{l}-0.35^{* *} \\
-0.32^{* *}\end{array}$ & $\begin{array}{l}-0.25^{* *} \\
-0.23^{*}\end{array}$ & $\begin{array}{l}-0.07 \\
-0.23^{*}\end{array}$ & $\begin{array}{l}0.52^{* *} \\
0.52^{* *}\end{array}$ & $\begin{array}{l}0.55^{* *} \\
0.53^{* *}\end{array}$ & & & & \\
\hline (12) Pleas & $\begin{array}{l}0.11 \\
0.10\end{array}$ & $\begin{array}{r}-0.03 \\
0.05\end{array}$ & $\begin{array}{l}-0.15^{*} \\
-0.03\end{array}$ & $\begin{array}{l}-0.21^{* *} \\
-0.13\end{array}$ & $\begin{array}{l}-0.13^{*} \\
-0.11\end{array}$ & $\begin{array}{l}-0.64^{* *} \\
-0.37^{* *}\end{array}$ & $\begin{array}{l}-0.50^{* *} \\
-0.31^{* *}\end{array}$ & $\begin{array}{l}-0.34^{* *} \\
-0.04\end{array}$ & $\begin{array}{l}0.54^{* *} \\
0.56^{* *}\end{array}$ & $\begin{array}{l}0.60^{* *} \\
0.41^{* *}\end{array}$ & $\begin{array}{l}0.41^{* *} \\
0.43^{* *}\end{array}$ & & & \\
\hline (13) Act & $\begin{array}{l}0.15^{*} \\
0.07\end{array}$ & $\begin{array}{r}-0.04 \\
0.09\end{array}$ & $\begin{array}{l}-0.16^{*} \\
-0.11\end{array}$ & $\begin{array}{l}-0.17^{*} \\
-0.21^{*}\end{array}$ & $\begin{array}{l}-0.14^{*} \\
-0.15\end{array}$ & $\begin{array}{l}-0.52^{* *} \\
-0.29^{* *}\end{array}$ & $\begin{array}{l}-0.36^{* *} \\
-0.19^{*}\end{array}$ & $\begin{array}{l}-0.25^{* *} \\
0.05\end{array}$ & $\begin{array}{l}0.50^{* *} \\
0.53^{* *}\end{array}$ & $\begin{array}{l}0.50^{* *} \\
0.28^{* *}\end{array}$ & $\begin{array}{l}0.37^{* *} \\
0.37^{* *}\end{array}$ & $\begin{array}{l}0.77^{* *} \\
0.71^{* *}\end{array}$ & & \\
\hline (14) Calm & $\begin{array}{l}0.10 \\
0.07\end{array}$ & $\begin{array}{l}0.14^{*} \\
0.19^{*}\end{array}$ & $\begin{array}{r}-0.03 \\
0.04\end{array}$ & $\begin{array}{l}-0.24^{* *} \\
-0.09\end{array}$ & $\begin{array}{l}-0.04 \\
-0.08\end{array}$ & $\begin{array}{l}-0.54^{* *} \\
-0.24^{\star *}\end{array}$ & $\begin{array}{l}-0.38^{* *} \\
-0.25^{* *}\end{array}$ & $\begin{array}{l}-0.32^{* *} \\
-0.02\end{array}$ & $\begin{array}{l}0.35^{* *} \\
0.28^{* *}\end{array}$ & $\begin{array}{l}0.47^{* *} \\
0.20^{*}\end{array}$ & $\begin{array}{l}0.26^{* *} \\
0.29^{* *}\end{array}$ & $\begin{array}{l}0.72^{* *} \\
0.71^{* *}\end{array}$ & $\begin{array}{l}0.60^{* *} \\
0.50^{* *}\end{array}$ & \\
\hline (15) Neuro & $-\overline{0.12}$ & $-\overline{0} 12$ & $-\overline{0} .13$ & $\overline{0.16}$ & $\overline{0.09}$ & $\overline{0.55^{* *}}$ & $\overline{0.24 * *}$ & $\overline{0.28 * *}$ & $-\overline{0.33 * *}$ & $-\overline{0.26 \text { ** }}$ & -0.17 & $-\overline{0.50 * *}$ & $-\overline{0.33 \text { ** }}$ & $-\overline{0.53 * *}$ \\
\hline Mean & $\begin{array}{l}14.78 \\
15.43\end{array}$ & $\begin{array}{l}31.16 \\
34.81\end{array}$ & $\begin{array}{r}6.00 \\
16.20\end{array}$ & $\begin{array}{l}79.11 \\
50.08\end{array}$ & $\begin{array}{l}1.47 \\
1.40\end{array}$ & $\begin{array}{l}2.54 \\
2.44\end{array}$ & $\begin{array}{l}1.96 \\
1.94\end{array}$ & $\begin{array}{l}2.32 \\
1.96\end{array}$ & $\begin{array}{l}3.29 \\
3.26\end{array}$ & $\begin{array}{l}2.72 \\
2.65\end{array}$ & $\begin{array}{l}2.36 \\
2.42\end{array}$ & $\begin{array}{l}2.90 \\
3.03\end{array}$ & $\begin{array}{l}2.88 \\
2.90\end{array}$ & $\overline{7.91}$ \\
\hline SD & $\begin{array}{l}10.88 \\
10.73\end{array}$ & $\begin{array}{l}28.47 \\
36.12\end{array}$ & $\begin{array}{r}4.72 \\
10.92\end{array}$ & $\begin{array}{l}37.37 \\
23.42\end{array}$ & $\begin{array}{l}0.67 \\
0.56\end{array}$ & $\begin{array}{l}0.76 \\
0.71\end{array}$ & $\begin{array}{l}0.84 \\
0.77\end{array}$ & $\begin{array}{l}1.02 \\
0.87\end{array}$ & $\begin{array}{l}0.52 \\
0.47\end{array}$ & $\begin{array}{l}0.77 \\
0.63\end{array}$ & $\begin{array}{l}0.74 \\
0.71\end{array}$ & $\begin{array}{l}0.59 \\
0.60\end{array}$ & $\begin{array}{l}0.67 \\
0.49\end{array}$ & $\overline{4.05}$ \\
\hline
\end{tabular}

differences between the samples, comparison of the means and SDs of the variables showed that the samples were very similar. Also, the correlations between variables were similar in both samples. A noteworthy result was that comparatively high correlations were found between both the negative and the positive RASC scales and the mood scales. The subjective symptoms (VAS and HAQ) showed moderate correlations with the RASC and mood scales, and the objective indicators of impairment status were only weakly related to subjective symptoms and the measures of psychological status.

\section{Measurement model}

To investigate the first two aims (see introduction) of the study the model included the five latent variables: impairment, subjective symptoms, negative RA cognitions, positive RA cognitions, and mood. Impairment was measured by a summated index consisting of a count of swollen joints (Ritchie's index in sample 2), disease duration, and CRP. Subjective symptoms were measured by self rated HAQ and pain ratings. Mood was measured by the pleasantness, activation, and calmness scales in the MACL. The scores of the three negative scales of the RASC were used as indicators of negative RA cognitions, and the scores of the three positive scales as indicators of positive RA cognitions.

Investigation of the third aim included a sixth latent variable, neuroticism. This variable was only measured in sample 2 and, thus, the model could not be cross validated in sample 1. To obtain at least two variables of neuroticism, the 24 items included in the scale were randomly split into two parallel "half scales". These half scales ( 12 items each) were then treated as equal effect indicators of the latent variable neuroticism.

In accordance with the classic factor analysis approach to measurement, ${ }^{61}{ }^{62}$ the studied variables were assumed to be effects of the corresponding latent variable, except impairment. A causal indicator model ${ }^{61}$ was viewed as more appropriate for impairment-that is, each of the measured indicators could add independently to determine the latent variable. This assumption was supported by the highly individual disease course characterising RA, the large fluctuations in disease activity from time to time, and effects of various interventions. The low correlations (table 1) found 


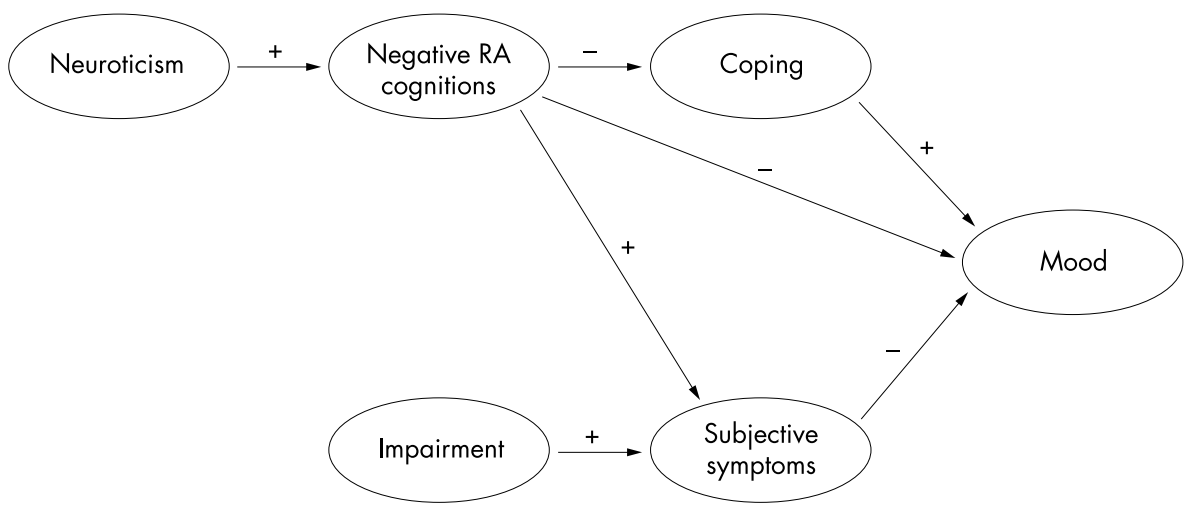

Figure 1 Hypothesised structural model between the latent variables. Note that the model with neuroticism included was only tested in sample 1. Positive influences are marked + and negative-

between the measures (disease duration, joint count, or Ritchie's index, and CRP) offered further support. Thus, the summated impairment index (see methods section) was set to equal the corresponding latent variable, with an error variance assumed to be 0.20 (giving a reliability estimate of 0.80 ).

The normality of the distribution of measured variables and number of scale steps were tested using the PRELIS program..$^{57}$ None of the variables measured deviated substantially from a normal distribution and all had more than 11 scale steps; thus, they could be treated as continuous variables.

In support of the validity of the measurement model, the hypothesised paths between latent variables and their observed variables were all found to be significant $(p<0.05)$, with expected valences and with residuals that were acceptably low.

\section{Structural models}

The next step was to test the structural models for the hypothesised relations between the latent variables. The aims were to test $(a)$ if the negative RA cognitions could be viewed as an independent variable that influenced all other self reported data; $(b)$ if these cognitions were related to impairment and; $(c)$ if, and to what extent, the personality dimension neuroticism is associated with the negative RA cognitions. Figure 1 shows the hypothesised structural model. Here it was assumed that impairment and negative RA cognitions independently influence perceived symptoms. Mood was expected to be influenced by negative RA cognitions, symptoms, and positive RA cognitions. The positive RA cognitions were also expected to be suppressed by the negative RA cognitions reflecting the neuroticism trait described in the introduction. ${ }^{39} 63$

Because data on neuroticism were only available for sample 2 , the first two aims were investigated separately and cross validated in both samples. Figure 2 shows the significant paths $(\mathrm{p}<0.05)$, standardised parameter estimates (sample 1 estimates are shown above those for sample 2), and the residuals for the model. The model fitted required only one revision to achieve an adequate fit-that is, removing a non-significant path from subjective symptoms to mood. The $\chi^{2}$ value in sample 1 was 114.7 (49 df), the RMSEA was 0.07, and the GFI was 0.92 . The model explained $57 \%$ of the variance in mood (the residual was 0.43 ). All of the variance was accounted for by negative and positive RA cognitions, both of which had significant direct effects on mood. As the negative RA cognitions also had a significant indirect effect on mood, via a suppression of the positive RA cognitions, it seemed that the negative cognitions dominated. Negative RA cognitions explained $28 \%$ of the variation in positive RA cognitions, thus most of the variance remained unexplained. Negative RA cognitions also significantly influenced subjective symptoms, as hypothesised. No significant direct effects were found from subjective symptoms to mood.

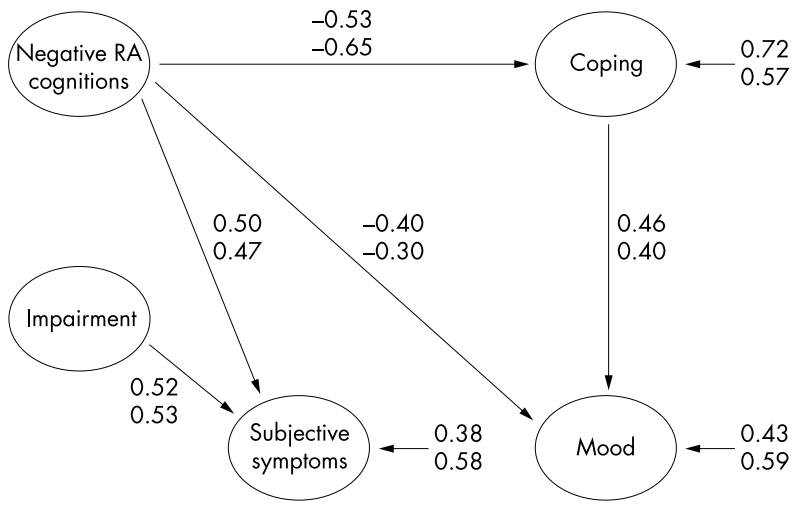

Figure 2 Structural model obtained between the five latent variables (neuroticism excluded). Only the significant parameter estimates $(p<0.05)$ are illustrated. The estimates from sample 1 are shown above those for sample 2. The proportions of explained variance of the dependent latent variables are shown with small arrows.

As hypothesised, impairment status had a significant effect only on subjective symptoms. This variable explained about half of the total explained variance in subjective symptoms; the other half was explained by negative RA cognitions. No significant relation was found between negative RA cognitions and impairment status.

Cross validation of the model in sample 2 yielded results similar to those obtained in sample 1. A similar fit was obtained when two of the 66 possible error covariances between variables were set free. (High covariances between error terms indicate the existence of relations between variables not accounted for in the hypothesised measurement model-that is, unexplained response biases of various types. $^{58}$ ) Both of these error covariances were small, had valences in the expected directions, and did not affect the significance of the structural parameter estimates. The parameter estimates were quite similar to those of sample 1 (upper $v$ lower estimates in fig 2). As in sample 1, the presumed path from subjective symptoms to mood was not significant. The $\chi^{2}$ value for the test of the model was $72.6(47 \mathrm{df})(\mathrm{p}=0.07)$, the RMSEA was 0.07 and the GFI was 0.90 . Thus, this cross validation supported the credibility of the model test for sample 1 . Differences in the demographic and clinical data between samples lent support to the generalisability of the results.

\section{The influence of neuroticism}

The model was tested in sample 2 with the measure of neuroticism included. As hypothesised, neuroticism was strongly related to negative RA cognitions, explaining $47 \%$ of the variance in negative RA cognitions (fig 3). Neuroticism 


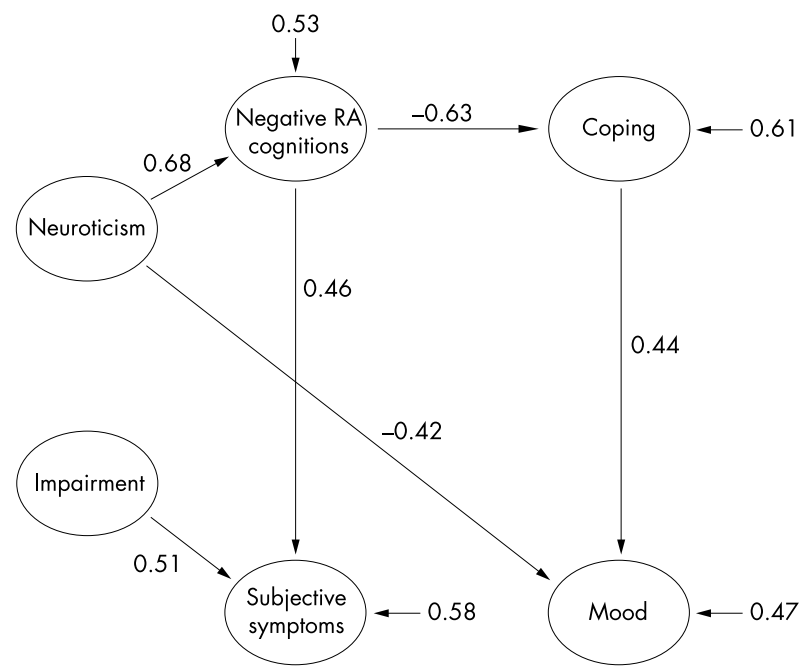

Figure 3 Path model obtained with neuroticism included (sample $2)$. Only the significant parameter estimates $(p<0.05)$ are illustrated. The estimates from sample 1 are shown above those for sample 2 . The proportions of explained variance of the dependent latent variables are shown with small arrows.

also showed a direct influence on mood, which diminished the direct influence of negative RA cognitions on mood found in the first model. Neuroticism was not directly related to subjective symptoms or positive RA cognitions and was unrelated to impairment status. On the other hand, neuroticism was indirectly related to all other self report measures, much the same as negative RA cognitions were in the first model. These relations were stronger with the psychological measures than with the illness measures. The $\chi^{2}$ value for this model was 116.7 (73 df), the RMSEA was 0.07 , and the GFI was 0.89 .

As a final test of the fit of the proposed models, alternative models were specified and compared; among others, the paths between the latent variables in the final models were reversed. However, all of them resulted in lower goodness of fit estimates.

\section{DISCUSSION}

The primary aim of the present study was to examine the relations between negative RA cognitions, positive RA cognitions, mood, and subjective symptoms versus objective measures of impairment status. To this end we used a newly developed questionnaire (RASC) that distinguishes between RA specific negative and positive illness cognitions.

Negative RA cognitions were hypothesised to be closely related to the neuroticism trait. They were thus expected to influence all other self reported data, but to be unrelated to the objectively measured indices of impairment. On the other hand, positive RA cognitions were expected to have a positive influence on mood, but also to be suppressed by the negative RA cognitions reflecting the neuroticism trait. ${ }^{63}$ We also divided the measures of disease status into those that were self rated (pain and ADL status) and those that were assessed objectively by a rheumatologist (disease duration, CRP, and joint impairment). The self rated indices of subjective symptoms were presumed to influence mood and to be influenced by the impairment measures. However, no direct relations were expected between impairment status and illness cognitions or mood (fig 1).

Analyses by SEM showed that negative RA cognitions could be viewed as having a relatively strong influence on all other self reported data. Thus, they seem to suppress both positive RA cognitions and mood, while exaggerating subjective symptoms (pain and ADL status). In fact, the subjective symptoms were equally well explained by the negative RA cognitions as by the index of impairment status. These results support the suggestion $\mathrm{s}^{30-32}{ }^{39}$ that negative illness cognitions, related to the neuroticism trait, may act as a common (and confounding) factor behind several types of self rated experiences in RA, including those that are commonly used for indicating illness status (pain and ADL status).

One important result is that these negative illness cognitions do not seem to evolve as a consequence of impairment, as no significant relations were found between impairment status and negative RA cognitions. Rather, tests of the model suggest that negative RA cognitions and impairment act as two independent and unrelated variables.

Another important result was that no significant direct path was found from subjective symptoms (pain and ADL status) to mood, as expected. This means that the moderate correlations between emotional wellbeing and subjective symptoms found in many studies could very well be explained by confounding from negative illness cognitions.

A further aim of the study was to examine the relation between negative RA cognitions and neuroticism. Thus, in this analysis (performed on sample 2 only) neuroticism was defined as an independent variable instead of negative RA conceptions. The hypothesis was that neuroticism would have significant effects on all self reported variables, particularly on the negative RA cognitions. These relations were also expected to decrease the influence from the negative RA cognitions found in the first analyses. In confirmation of our hypothesis, it was found that neuroticism alone explained nearly $50 \%$ of the variance in negative RA cognitions (fig 3). Neuroticism also had a direct and relatively strong effect on mood, which in turn diminished the direct influence from the negative RA cognitions. However, neuroticism was not directly related to positive RA cognitions or to subjective symptoms. Instead, the influences from neuroticism on these variables could be interpreted as indirect via the RA specific negative cognitions ( fig $3)$. On the whole, however, this second path analysis supports the hypothesis that the negative RA specific cognitions depend largely on the neuroticism trait.

Our results corroborate other findings suggesting that a temperamental disposition towards neuroticism and negative cognitions influences other types of self rated data among patients with RA. ${ }^{38}$ As discussed in the introduction, such findings may have pessimistic implications for the effects of psychological interventions or patient training on subjective wellbeing in the long run. However, the results should not be interpreted too categorically; none of the dependent latent variables defined in the models had more than about 50\% explained variance. This suggests that, even when neuroticism or negative RA cognitions and degree of impairment are controlled for, there are substantial variations in positive RA cognitions, mood, and subjective symptoms that remain unexplained. Such variations are related to individual and situational factors not included in the models and allow for the possibility of changing emotional wellbeing despite temperamental dispositions or impairment. It has also been shown that objective changes in health may affect subjective wellbeing to some degree, even when personality differences are held constant. ${ }^{64}$

The present study does not imply that patients with RA have particularly high levels of neuroticism or emotional distress. On the contrary, the mean level of neuroticism in our sample of patients with RA was 7.9, which is very close to the mean level of 8.1 in the Swedish population. ${ }^{55}$ This indicates that patients with RA are not higher in neuroticism than people in general. Similarly, several studies have shown that patients with RA are surprisingly high in emotional wellbeing, despite their profound pain and the progressively disabling course of the disease. ${ }^{126}$ The purpose of the study was to suggest some explanations as to why patients with RA may differ in their symptom experiences and emotional wellbeing, despite similar degrees of impairment. 
Limitations in the design and the statistical methods used in the present study need comment. The models specified and tested in the two independent samples support the hypotheses that negative RA cognitions and neuroticism strongly influence positive RA cognitions, subjective symptoms, and mood, but are unrelated to impairment status. However, the study was cross sectional in design and the results were principally based on correlation analyses. To provide further evidence on the causal relations between these variables it is important to perform longitudinal and prospective studies in which changes in each variable may be controlled for over time. Controlled intervention studies with more persistent follow up are also of importance to examine the degree to which it is possible to change subjective perceptions of illness and emotional wellbeing in the long run.

\section{ACKNOWLEDGEMENTS}

Support for this research was provided by grants from the Swedish Council for Planning and Coordination of Research, the Swedish National Association against Rheumatism, the Foundation for Aid to the Disabled in Scania, and the Thure Carlsson Memorial Trust. We are also very grateful to the late Professor Kaare Berglund for his inspiration and participation in this project. We dedicate this article to his memory.

\section{Authors' affiliations}

L-O Persson, Health Care Research Unit, Institute of Internal Medicine, Sahlgrenska University Hospital, Göteborg University, Sweden D Sahlberg, Department of Internal Medicine, Halmstad Hospital, Sweden

\section{REFERENCES}

1 Hawley DJ, Wolfe F. Anxiety and depression in patients with rheumatoid arthritis: a prospective study of 400 patients. J Rheumatol 1988; 15:932-41.

2 Cassileth BR, Lusk EJ, Strouse TB. Psychosocial status in chronic illness: a comparative analysis of six diagnostic groups. $N$ Engl J Med 1984;311:506-11.

3 McFarlane AC, Brooks PM. An analysis of the relationship between psychological morbidity and disease activity in rheumatoid arthritis. J Rheumatol 1988;15:926-31.

4 Berglund K, Persson L-O. Dimensions of psychological adjustment to illness in rheumatoid arthritis: a preliminary report. Scand J Rheumatol 1990; 17:263-71.

5 Young LD. Psychological factors in rheumatoid arthritis. J Consult Clin Psychol 1992;60:619-27.

6 Persson L-O, Berglund K. A structure of self- and illness conceptions in rheumatoid arthritis: a phenomenological approach. J Psychosom Res 1996;40:535-49.

7 Nicassio PM, Wallston KA, Callahan LF, Herbert M, Pincus T. The measurement of helplessness in rheumatoid arthritis. The development of the arthritis helplessness index. J Rheumatol 1985;12:462-7.

8 Stein MJ, Wallston KA, Nicassio PM. Factor structure of the arthritis helplessness index. J Rheumatol 1988; 15:427-32.

9 Smith TW, Peck JR, Ward JR. Helplessness and depression in rheumatoid arthritis. Health Psychol 1990:9:377-89.

10 Stein MJ, Wallston KA, Nicassio PM, Castner NM. Correlation of clinical classification schema for the arthritis helplessness subscale. Arthritis Rheum 1988;31:876-81.

11 Lorig K, Chastain RL, Ung E, Shoor S, Holman HR. Development and evaluation of a scale to measure perceived self-efficacy in people with arthritis. Arthritis Rheum 1989:32:37-44.

12 O'Leary A, Shoor S, Lorig K, Holman HR. A cognitive-behavioral treatment for rheumatoid arthritis. Health Psychol 1988;7:527-44.

13 Regan CA, Lorig K, Thoresen CE. Arthritis appraisal and ways of coping: scale development. Arthritis Care Res 1988;3:139-50.

14 Blalock SJ, DeVellis BM, Devellis RF. Social comparison among individuals with rheumatoid arthritis. J Appl Psychol 1989;19:665-80.

15 Buescher KL, Johnston JA, Parker JC, Smarr KL, Buckelew SP, Anderson SK, et al. Relationship of self-efficacy to pain behavior. J Rheumatol 1991;18:968-72.

16 Beck AT. Cognitive therapy and the emotional disorders. New York: International Universities Press, 1976

17 Keefe FJ, Brown GK, Wallston KA, Caldwell DS. Coping with rheumatoid arthritis pain: catastrophizing as a maladaptive strategy. Pain 1989:37:51-6.

18 Smith TW, Peck JR, Milano RA, Ward JR. Cognitive distortion in rheumatoid arthritis: relation to depression and disability. J Consult Clin Psychol 1988;56:412-6.

19 Flor H, Turk, DC. Chronic back pain pain and rheumatoid arthritis: predicting pain and disability from cognitive variables. J Behav Med $1988 ; 11: 251-65$.
20 Gil KM, Williams DA, Keefe FJ, Beckham JC. The relationship of negative thoughts to pain and psychological distress. Behav Ther 1990;21:349-52.

21 Lazarus RS, Folkman S. Stress, appraisal and coping. New York: Springer, 1984.

22 Vitaliano PP, Russo J, Carr JE, Maiuro RD, Becker J. The ways of coping checklist: revision and psychometric properties. Multivar Behav Res 1985;20:3-26.

23 Manne SL, Zautra AJ. Couples coping with chronic illness: women with rheumatoid arthritis and their healthy husbands. J Behav Med $1990 ; 13: 327-42$

24 Parker J, McRae C, Smarr K, Beck N, Frank R, Anderson S, et al. Coping strategies in rheumatoid arthritis. J Rheumatol 1988;15:137683.

25 Revenson TA, Felton BJ. Disability and coping as predictors of psychological adjustment to rheumatoid arthritis. J Consult Clin Psychol 1989:57:344-8.

26 Rosenstiel AK, Keefe FJ. The use of coping strategies in chronic low back pain patients: relationship to patient characteristics and curren adjustment. Pain 1983;17:33-44.

27 Parker JC, Smarr KL, Buescher KL, Phillips LR, Frank RG, Beck NC, et al. Pain control and rational thinking. Arthritis Rheum 1989;32:984-90.

28 Beckham JL, Keefe FJ, Caldwell DS, Roodman AA. Pain coping strategies in rheumatoid arthritis: relationships to pain, disability, depression and daily hassles. Behav Ther 1991;22:113-24.

29 Hagglund KJ, Haley WE, Revelle JD, Alarcón GS. Predicting individua differences in pain and functional impairment among patients with rheumatoid arthritis. Arthritis Rheum 1989;32:851-8.

30 Watson D, Pennebaker JW. Health complaints, stress and distress: exploring the central role of negative affectivity. Psychol Rev 1988;96:234-54

31 Costa PT, McCrae RR. Influence of extraversion and neuroticism on subjective well-being: happy and unhappy people. J Pers Soc Psychol 1980;38:668-78

32 Costa PT, McCrae RR. Neuroticism, somatic complaints and disease: is the bark worse than the bite? J Pers 1987:55:299-316.

33 Harkins SW, Price DD, Braith J. Effects of extraversion and neuroticism on experimental pain, clinical pain and illness behavior. Pain 1989;36:209-18

34 Larsen RJ. Neuroticism and selective encoding and recall of symptoms: evidence from a combined concurrent-retrospective study. J Pers Soc Psychol 1992;62:480-8.

35 Ormel J, Wohlfart T. How neuroticism, long-term difficulties, and life situation change influence psychological distress: a longitudinal model. J Pers Soc Psychol 1991;60:744-55.

36 Bolger N, Schilling EA. Personality and the problems of everyday life: the role of neuroticism in exposure and reactivity to daily stressors. J Pers 1991;59:355-86

37 Bolger N, Zuckerman A. A framework for studying personality in the stress process. J Pers Soc Psychol 1995;69:890-902

38 Affleck G, Tennen H, Urrows S, Higgins P. Neuroticism and the pain-mood relation in rheumatoid arthritis: insights from a prospective daily study. J Consult Clin Psychol 1992;60:1 19-26.

39 Clark LA, Watson D. Mineka S. Temperament, personality, and the mood and anxiety disorders. J Abnorm Psychol 1994;103:103-16.

40 Fries JF, Spitz P, Kraines RG, Holman HR. Measurement of patient outcome in arthritis. Arthritis Rheum 1980;23:137-45.

41 Ekdahl C, Eberhardt K, Andersson SI, Svensson B. Assessing disability in patients with rheumatoid arthritis. Scand J Rheumatol 1988; 17:263-71.

42 DeVellis RF, Blalock SJ. Psychological and educational interventions to reduce arthritis disability. In: Newman SP, Shipley M, eds. Balliére's clinical rheumatology. Vol 7, No 2. Psychological aspects of rheumatic disease. London: Balliére Tindall, 1993.

43 Marcus H. Self-schemata and processing information about the self. J Pers Soc Psychol 1977;35:63-78.

44 Marcus H. Unresolved issues of self-representation. Cogn Ther Res 1990; 14:241-53.

45 Wright BA. Physical disability: a psychosocial approach. New York: Harper and Row, 1983

46 Stensman R. Severly mobility-disabled people assess the quality of their lives. Scand J Rehabil Med 1985;17:87-99.

47 Montgomery H, Persson L-O, Rydén A. Importance and attainment of life values among disabled and non-disabled people. Scand J Rehabil Med 1996;28:233-40.

48 Arnett FC, Edworthy SM, Bloch DA, McShane DJ, Fries JF, Cooper NS, et al. The American Rheumatism Association 1987. Revised criteria for the classification of rheumatoid arthritis. Arthritis Rheum 1988;31:315-24

49 Ritchie DM, Boyle JA, Mclnnes JM, et al. Clinical studies with an articular index for the assessment of joint tenderness in patients with rheumatoid arthritis. Q J Med 1968:37:716-7.

50 Sjoeberg L, Svensson E, Persson L-O. The measurement of mood. Scand J Psychol 1979;20:1-18

51 Augustinsson L-E, Sullivan L, Sullivan M. Physical, psychologic and social function in chronic pain patients after epidural spinal electrical stimulation. Spine 1986;11:111-9.

52 Lundqvist C, Siosteen A, Blomstrand C, Lind B, Sullivan M. Spinal cord injuries. Part 1: clinical and functional status. Spine 1991;16:78-83.

53 Ahlmén M, Bjelle A, Sullivan M. Prediction of team care effects in outpatients with rehumatoid arthritis. J Rheumatol 1991;18:1655-61.

54 Eysenck HJ, Eysenck SBG: Manual of the Eysenck personality inventory. London: University of London Press, 1964. 
55 Bederoff-Petersson A. EPI: Eysenck personality inventory: synpunkter och några svenska undersökningsdata. Stockholm: Skandinaviska testförlaget, 1971. (In Swedish.)

56 Hayduk, LA. Structural equation modeling with LISREL: essentials and advances. Baltimore: Johns Hopkins University Press, 1987.

57 Joereskog KG, Soerbom D. LISREL VII:A guide to the program and applications. Chicago: SPSS, 1989.

58 Bollen KA. Structural equations with latent variables. New York: Wiley, 1989

59 Raykov R, Tomer A, Nesselroade JR. Reporting structural equation modeling results in psychology and aging: some proposed guidelines. Psychol Ageing 1991;6:499-503.
60 Loehlin JC. Latent variable models: an introduction to factor, path, and structural analysis. Hillsdale NJ: Lawrence Erlbaum Associates, 1992.

61 Bollen K, Lennox R. Conventional wisdom on measurement: a structural equation perspective. Psychol Bull 1991;110:305-14.

62 Nunnally JC, Bernstein IH. Psychometric theory. New York: McGraw-Hill, 1994.

63 Taylor SE. Asymmetrical effects of positive and negative events: the mobilization-minimization hypothesis. Psychol Bull 1991;1 10:67-85.

64 Brief AP, Houston-Butcher A, George JM, Link KE. Integrating bottom-up and top-down theories of subjective well-being: the case of health. J Consult Clin Psychol 1993;64:646-53.

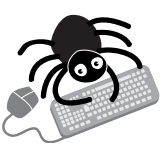

Please visit the Annals of Rheumatic Diseases website (www.annrheumdis. com) for link to this full article. physically demanding or mentally stressful working environment seems to increase the risk of musculoskeletal symptoms. But research now suggests that employees are most susceptible when simultaneously exposed to both sets of pressures.

Manual workers and administrative employees working for one company were surveyed on the physical and psychosocial demands of their jobs and the prevalence of musculoskeletal symptoms. Of the 869 responses, 564 were classifiable according to degree of exposure to the physical and/or psychosocial elements of their job.

Physical demands included the amount of lifting, and size of the load, and the length of time spent seated while exposed to vibration. Psychosocial factors included mental demands, job control, and levels of support from managers and coworkers.

Around a third of the workers reported having had musculoskeletal problems in the neck, shoulders, hands, and wrists in the preceding seven days. Over half $(55 \%)$ reported symptoms in their arms.

Workers exposed to either high physical or high psychosocial demands were over seven times as likely to report musculoskeletal symptoms. After adjusting for age, gender, and years in post, the highest and most significant risk for symptoms in the hand, wrist, or arms was found among those exposed to both high physical and psychosocial demands.

Psychosocial factors were more important when physical demands were high than when these were low, suggesting an interplay between these factors conclude the authors. Ergonomic strategies would do well to take account of psychosocial factors in the workplace as well, they say.

\ Occupational and Environmental Medicine 2002;59:269-277 